\title{
Comparing the diagnostic value of Echocardiography In Stroke (CEIS) - results of a prospective observatory cohort study
}

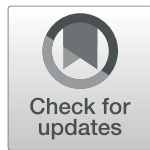

Marlena Schnieder ${ }^{1 * \dagger}$, Mohammed Chebbok ${ }^{2 \dagger}$, Michael Didié ${ }^{2}$, Frieder Wolf ${ }^{2}$, Mostafa Badr ${ }^{1}$, Ibrahim Allam , Mathias Bähr ${ }^{1}$, Gerd Hasenfuß ${ }^{2}$, Jan Liman ${ }^{1+}$ and Marco Robin Schroeter ${ }^{2 \dagger}$

\begin{abstract}
Background: Echocardiography is one of the main diagnostic tools for the diagnostic workup of stroke and is already well integrated into the clinical workup. However, the value of transthoracic vs. transesophageal echocardiography (TTE/TEE) in stroke patients is still a matter of debate. Aim of this study was to characterize relevant findings of TTE and TEE in the management of stroke patients and to correlate them with subsequent clinical decisions and therapies.
\end{abstract}

Methods: We evaluated $n=107$ patients admitted with an ischemic stroke or transient ischemic attack to our stroke unit of our university medical center. They underwent TTE and TEE examination by different blinded investigators.

Results: Major cardiac risk factors were found in 8 of 98 (8.2\%) patients and minor cardiac risk factors for stroke were found in 108 cases. We found a change in therapeutic regime after TTE or TEE in 22 (22.5\%) cases, in 5 (5\%) cases TEE leads to the change of therapeutic regime, in 4 (4\%) TTE and in 13 cases (13.3\%) TTE and TEE lead to the same change in therapeutic regime. The major therapy change was the indication to close a patent foramen ovale (PFO) in 9 (9.2\%) patients with TTE and in $10(10.2 \%)$ patients with TEE $(p=1.000)$.

Conclusion: Major finding with clinical impact on therapy change is the detection of PFO. But for the detection of PFO, TTE is non inferior to TEE, implicating that TTE serves as a good screening tool for detection of PFO, especially in young age patients.

Trial registration: The trial was registered and approved prior to inclusion by our local ethics committee $(1 / 3 / 17)$.

Keywords: Stroke, Echocardiography, Patent foramen ovale, Cardio-embolic stroke

\section{Background}

About $20-40 \%$ of ischemic strokes are of cardioembolic source [1]. Atrial fibrillation is one major cardiac risk factor, besides several others such a patent foramen

\footnotetext{
* Correspondence: marlena.schnieder@med.uni-goettingen.de

†Marlena Schnieder, Mohammed Chebbok, Jan Liman and Marco Robin Schroeter contributed equally to this work.

${ }^{1}$ Department for Cardiology \& Pneumology/Heart Center, University Medical Center Göttingen, Robert-Koch Straße 40, 37075 Göttingen, Germany

Full list of author information is available at the end of the article
}

ovale (PFO), intracardial thrombi, aortic plaques or valvular disease [2]. Cardiac and aortic sources of emboli such as intracardial thrombi and aortic plaques are better visualized in transesophageal echocardiography (TEE), which is more cost intensive and semi-invasive, than in transthoracic echocardiography (TTE) [3] . Additionally there is also evidence for a higher sensitivity of TEE detecting cardioembolic sources of embolic stroke compared to TTE [4]. Moreover TEE is also believed to be superior in the workup of the diagnostic for PFO [3].

C C The Author(s). 2021 Open Access This article is licensed under a Creative Commons Attribution 4.0 International License, which permits use, sharing, adaptation, distribution and reproduction in any medium or format, as long as you give appropriate credit to the original author(s) and the source, provide a link to the Creative Commons licence, and indicate if changes were made. The images or other third party material in this article are included in the article's Creative Commons licence, unless indicated otherwise in a credit line to the material. If material is not included in the article's Creative Commons licence and your intended use is not permitted by statutory regulation or exceeds the permitted use, you will need to obtain permission directly from the copyright holder. To view a copy of this licence, visit http://creativecommons.org/licenses/by/4.0/ The Creative Commons Public Domain Dedication waiver (http://creativecommons.org/publicdomain/zero/1.0/) applies to the data made available in this article, unless otherwise stated in a credit line to the data. 
Recommendations are based on earlier studies, which showed a higher detection rate of PFO in TEE [5]. Despite being less specific transcranial doppler provided a higher detection rate of right-left shunts in comparison to TTE [6]. Without application of contrast agent and potential underdetection of PFO a subgroup analysis of the NAVIGATE-ESUS trial, TEE was more potent in detection of PFO than TTE [7]. Moreover, recent metaanalysis could demonstrate that TEE was superior to TTE in detecting intracardial abnormalities. This raises the question of the impact on change in therapy [8]. This prospective study aims to compare the diagnostic relevance of TEE to TTE in the perspective of additional abnormal findings and with an emphasis on clinical relevance for implication on change in therapeutical regime.

\section{Methods}

From November 2017 till October 2019 patients admitted to our stroke unit or neurological intensive care unit of our university medical center with a transient ischemic attack or ischemic stroke were prospectively enrolled in this study. All patients eligible for the study underwent a standard diagnostic work up including a 12-lead electrocardiogram (ECG), holter-ECG with a duration of $72 \mathrm{~h}$, duplex sonography of the head and neck arteries, a routine blood examination including HbA1c and the lipid status as well as infections parameters and creatinine. Inclusion criteria were age over 18 and patients had to be able to give capacity for consent. Exclusion criteria were a body mass index $>35 \mathrm{~kg} / \mathrm{m} 2$, due to the reduced echocardiographic ability in obese patients and therefore per se decreased diagnostic value of TTE; as well as a mechanical heart valve and a suspected endocarditis would be a mandatory implication for TEE. The trial was registered and approved prior to inclusion by our local ethics committee $(1 / 3 / 17)$, informed consent was obtained from all patients. Neurological characteristics, such as the etiology of the stroke, National Institute of Health Score (NIHSS) and modified Rankin Scale (mRS) were collected as well as the cardiovascular risk factors (CVRF) and potential anticoagulation or antithrombotic drugs. Each patient underwent subsequently transesophageal and transthoracic echocardiography following a predefined protocol by different experienced echocardiologists (F.W, M.C and M.D). They were blinded to patients imaging and clinical data, especially regarding echocardiography results. To minimize/optimize interrater variability/reliability the cardiologist analyzed 25 different predefined echocardiography recordings regarding major echocardiographic findings prior to the enrollment of study patients. Transesophageal and transthoracic echocardiography (TEE/ TTE) with IE33, CX50 and X7-2t probe (Philips Medical Systems, Eindhoven, Netherlands) or Vivid E9 and 6VT-
Dprobe (GE Healthcare, USA) was performed by experienced cardiological examiners using a standard operating procedure. The collected data included the presence of a thrombus in the left atrial appendage (LAA), left atrium (LA) or the left ventricle (LV), measurements of LAA flow velocity, the LA dimension, the ejection fraction of the left ventricle as well as the presence of a PFO or a PFO combined with an atrial septum aneurysm (ASA), myxoma, aortic thrombus or plaque, the examination of heart valves including presence of calcifications or suspected endocarditis. The size of the PFO was defined by the number of bubbles passing in the left atrium. $<6$ bubbles were defined as small, $6-26$ as medium and $>26$ as large PFO. Echocardiographic risk findings were divided in major and minor cardiac risk factors of cardio embolic stroke [9]. Descriptive statistics were presented using mean and standard deviation. Comparisons between detections rates in TTE and TEE were made using McNemar's test. Groups comparisons between categorical variables were made using chisquared test or Fischer's exact test. With a $p$-value < 0.05 results were considered at statistically significant. Statistical analysis was performed using IBM SPSS Statistics vs 26.

\section{Results}

From November 2017 till October 2019 we enrolled 107 patients in our study. In this timespan 98 of 107 patients received TEE and TTE. Two patients withdrew consent. One patient was excluded due to a possible endocarditis. Due to anatomical reasons, pharyngeal bleeding or strong retching TEE was not possible in 6 patients (Fig. 1).

Baseline characteristics and neurological characteristics are listed in Table 1. 30 (30.6\%) patients were female, 68 (60.4\%) were male. Arterial hypertension was the most common CVRF with $62.2 \%$ (61 patients). Moreover, 55 (56.1\%) suffered from dyslipidemia and 13 (13.3\%) from diabetes. Atrial fibrillation and coronary heart disease were present in $10(10.2 \%)$ patients respectively. The major etiology of stroke showed to be cardio-embolic in 26 patients (26.5\%), while the localization was predominantly in the MCA territory $(n=66 ; 67.3 \%)$. The NIHSS as well as mRS at admission were rather low with in mean $2.7( \pm 3.9)$ and $1.2( \pm 1.2)$.

Potential cardiac risk factors detected by echocardiography were found in $61(62 \%)$ patients. Several of them had multiple findings, which together showed 116 times potential embolic risk factors. Major cardiac risk factors were found in 8 of $98(8.2 \%)$ patients, 4 in TTE and 5 in TEE (Table 2). One myxoma and two fibroelastoma were found as major cardic risk factors. One patient with fibroelastoma was referred to a cardiac valve operation; the other received antithrombotic medication and a 


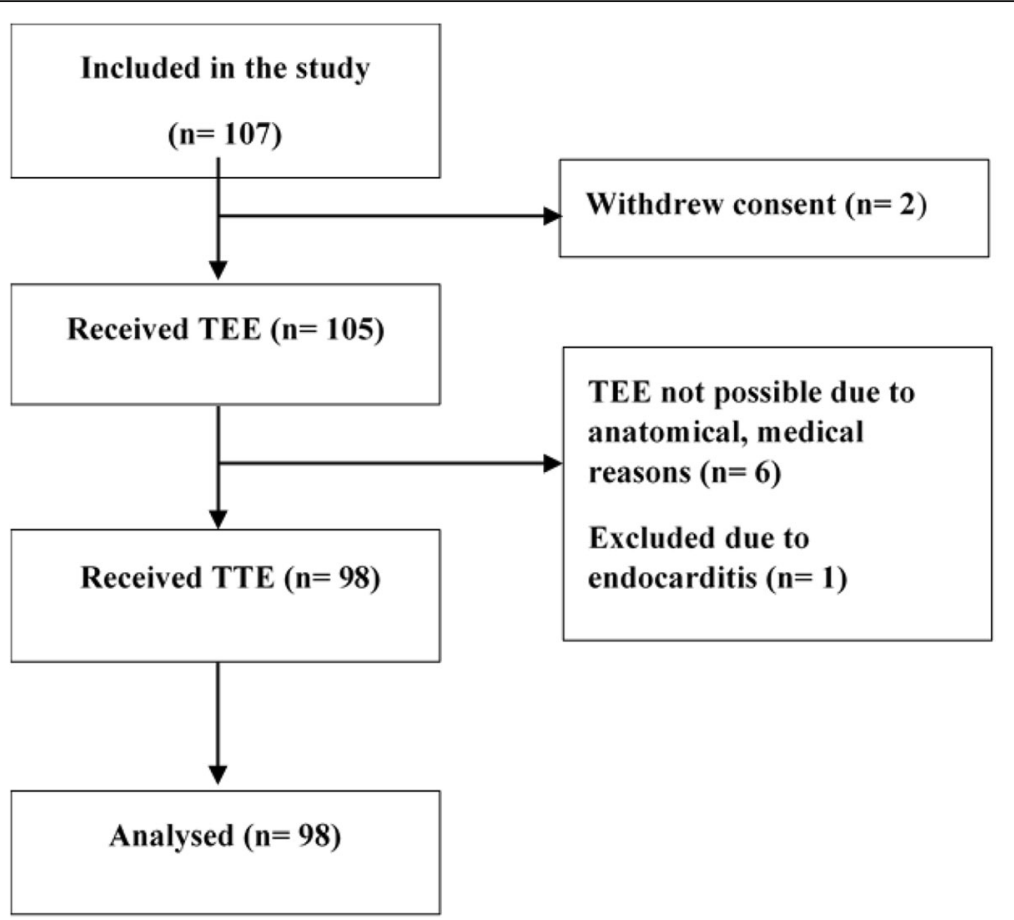

Fig. 1 Flowchart of the patient selection

follow-up TEE after 6 months due to the small size of the fibroelastoma. The patient with the myxoma received oral anticoagulation, since further treatment was not desired by the patient.

Due to the low number of findings in each major cardiac risk factor, no information about statistical significance of differences in TTE and TEE could be obtained. Minor cardiac risk factors for stroke were found in 108 cases, of whom 41 were detected via TTE and 105 via TEE (Table 3).

PFO was detected in 18 (18.4\%) patients by TEE and 19 (19.4\%) by TTE. One false positive result occurred in TEE group. After further diagnostics it appeared as a pulmonary right-left shunt. We did find significant more mitral-valve prolapses in TEE comparing to TTE (9 (9.2\% vs. $1(1 \%) ; p=0.004)$ as well as annular calcifications $(27(27.6 \%)$ vs. $5(5.1 \%) ; p<0.001)$ and aortic plaques $(30(30.6 \%)$ vs. $0(0 \%) ; \mathrm{p}<0.001)$. Looking closer at the clinical relevance of those echocardiographic findings, we saw an overall change in therapeutic regime by TTE and/or TEE in $22(22.5 \%)$ cases. In 5 (5\%) cases of TEE, in 4 (4\%) TTE and in 13 cases (13.3\%) TTE and TEE lead to a change in therapeutic regime. Stroke relevant therapeutic changes were present in 13 (13.2\%) cases, while other findings were cardiac related therapy changes (Table 4).

The major change was the indication of PFO-closure in $9(9.2 \%)$ patients with TTE and in 10 (10.2\%) patients with TEE $(p=1.000)$. Regarding the size of the PFO, there was slight difference in detection. In TTE, two showed to be small, two moderate and 14 large sized, while in in TEE, one was small, six moderate and eleven large sized $(p=0.619)$. Frequent findings of other minor cardiac risk factors, which were more likely to be detected in TEE such as aortic plaque, annular mitral valve calcifications or mitral valve prolapse did not lead to a change in therapeutic regime. Since TEE is especially recommended in younger patients with years of age under 61 , we analyzed for possible differences in detection rates depending on the age of the patients. In total 42 patients were under 61 years. In this group major cardiac risk factors were rare and found in $7.1 \%$ of patients (Table 5).

In TEE, two patients with fibroelastoma were detected and in TTE one patient had a reduced left ventricular ejection fraction under $30 \%$. Furthermore, no other major cardiac risk factors were found in TTE nor in TEE. Regarding minor cardiac risk factors, PFO is the most frequent finding in TEE 12/42 (28.6\%) and TTE $13 / 42(31 \%)(p=1.0)$. Other risk factors such as atrial septum aneurism were shown in $7 / 42(16.7 \%)$ in TEE and $4 / 42(9.5 \%)$ in TTE $(p=0.375)$. Spontaneous echocontrast was found in $1 / 42(2.4 \%)$ in TEE and TTE, aortic plaques in 6/42 (14.25\%) in TEE and none in TTE $(p=0.031)$, annular mitral valve sclerosis in $4 / 42(9.5 \%)$ in TEE and in $1 / 42(2.4 \%)$ in TTE $(p=0.250)$. Mitral valve prolapse was found in $4 / 42$ (9.5\%) in TEE and none in TTE $(p=0.125)$. Other minor cardiac risk 
Table 1 baseline and neurological characteristics

\begin{tabular}{ll}
\hline baseline characteristics & \\
\hline female & $\mathbf{3 0}(\mathbf{3 0 . 6 \% )}$ \\
\hline age (years) & $63.6( \pm 12.5)$ \\
body mass index & $26.3( \pm 4.1)$ \\
smoking & $28(28.6 \%)$ \\
arterial hypertension & $61(62.2 \%)$ \\
dyslipidemia & $55(56.1 \%)$ \\
diabetes mellitus & $13(13.3 \%)$ \\
atrial fibrillation & $10(10.2 \%)$ \\
coronary heart disease & $10(10.2 \%)$ \\
heart failure & $11(11.2 \%)$ \\
thrombophilia & $1(1 \%)$ \\
neurological characteristics & \\
cardio-embolic & $26(26.5 \%)$ \\
macroangiopathy & $9(9.2 \%)$ \\
microangiopathy & $20(20.4 \%)$ \\
ESUS & $11(11.2 \%)$ \\
Cryptogenic & $18(18.4 \%)$ \\
other etiology & $14(14.3 \%)$ \\
NIHSS at admission & $2.7( \pm 3.9)$ \\
mRS at admission & $1.2( \pm 1.2)$ \\
MCA & \\
ACA & $66(67.3 \%)$ \\
mechstory & $1(1 \%)$ \\
\hline & $10(10.2 \%)$ \\
BA & $19(19.4 \%)$ \\
\hline
\end{tabular}

$\pm= \pm$ standard deviation, ESUS embolic stroke of unknown source, NIHS $S$ National Institute of Health Stroke Score, $m R S$ modified Rankin Scale, $M C A$ middle cerebral arteries, $A C A$ anterior cerebral arteries, PCA posterior cerebral arteries, $B A$ basilar artery

Table 2 Major cardiac risk factors found by echocardiography

\begin{tabular}{llll}
\hline Major cardiac risk factor & TTE & TEE & p-value \\
\hline LV-EF $<30 \%$ & $2(2 \%)$ & n.a. & n.a \\
LA thrombus & none & none & n.a \\
LAA thrombus & none & none & n.a \\
LV thrombus & $1(1 \%)$ & none & n.a \\
Mitral valve stenosis & $1(1 \%)$ & $1(1 \%)$ & n.a \\
Atrial myxoma & none & $1(1 \%)$ & n.a \\
Infective endocarditis & none & $1(1 \%)$ & n.a \\
Cardiac fibroma & none & $2(2 \%)$ & n.a \\
\hline
\end{tabular}

TTE transthoracic echocardiography, TEE transesophageal echocardiography, $L V$-EF left ventricular ejection fraction, $L A$ left atrium, $L A A$ left atrial appendage, $L V$ left ventricle, n.a. not applicable
Table 3 Minor cardiac risk factors found by echocardiography

\begin{tabular}{llll}
\hline Minor cardiac risk factor & TTE & TEE & p-value \\
\hline Mitral valve prolapse & $1(1 \%)$ & $9(9.2 \%)$ & 0.008 \\
Mitral annular calcification & $5(5.1 \%)$ & $27(27.6 \%)$ & $<0.001$ \\
Calcified aortic stenosis & $6(6.1 \%)$ & $5(5.1 \%)$ & 1.000 \\
Patent foramen ovale & $19(19.4 \%)$ & $18(18.4 \%)$ & 1.000 \\
Spontaneous echo contrast & $2(2 \%)$ & $5(5.1 \%)$ & 0.375 \\
Atrial septum aneurysm & $6(6.1 \%)$ & $11(11.2 \%)$ & 0.180 \\
Left ventricular aneurysm & $2(2 \%)$ & none & n.a. \\
Aortic plaque & none & $30(30.6 \%)$ & $<0.001$ \\
\hline TE transthoracic echocardiography, TEE transesophageal echocardiography, \\
n.a. not applicable
\end{tabular}

factors such as LV aneurysm or aortic stenosis were not found in TEE or TTE. Comparing the findings of younger $(\leq 60$ years) to older patients, there were a higher rate of PFO (12 (28.6\%) vs. $6(10.7 \%) ; p=0.034)$ in younger patients and higher rate of aortic plaque (6 (14.3\%) vs. $24(44.4 \%) ; p=0.002)$ and mitral annular calcifications $(4(9.5 \%)$ vs. $23(41.1 \%) ; p=0.001)$ in older patients. In $14 / 42(33.3 \%)$ of younger patients, echocardiography lead to a therapy change. This was mainly the detection respectively closure of PFO in $8 / 42$ (19\%) patients after TEE and in 7/42 (16.7\%) patients after TTE $(p=1.000)$. One patient $(2.4 \%)$ received oral anticoagulation after TEE and none after TTE. Other therapy changes were related to cardiac therapy and not stroke relevant. One patient (2.4\%) received dual platelet inhibition after TTE and none after TEE. The same hold true for coronary angiography, coronary artery bypass graft and implantation of cardiac stent. Two out of 42 (4.8\%) patients received heart failure therapy after TTE and One (2.4\%) after TEE.

Table 4 Impact of echocardiography on therapy change

\begin{tabular}{|c|c|c|c|}
\hline therapy change & TTE & TEE & p-value \\
\hline \multicolumn{4}{|l|}{ stroke related therapy changes } \\
\hline closure of patent foramen ovale & $9(9.2 \%)$ & $10(10.2 \%)$ & 1.000 \\
\hline antibiotic therapy & none & $1(1 \%)$ & n.a. \\
\hline oral anticoagulation & none & $2(2 \%)$ & n.a. \\
\hline \multicolumn{4}{|l|}{ cardiac related therapy change } \\
\hline heart failure therapy & $2(2 \%)$ & $1(1 \%)$ & n.a. \\
\hline coronary angiography & $5(5.1 \%)$ & $3(3.1 \%)$ & 0.500 \\
\hline coronary stent & $1(1 \%)$ & none & n.a. \\
\hline heart valve operation & $1(1 \%)$ & $1(1 \%)$ & n.a. \\
\hline coronary artery bypass graft & $2(2 \%)$ & $1(1 \%)$ & n.a. \\
\hline dual antiaggregation therapy & $1(1 \%)$ & none & n.a. \\
\hline other & $4(4.1 \%)$ & $4(4.1 \%)$ & 1.000 \\
\hline
\end{tabular}

TE transthoracic echocardiography, TEE transesophageal echocardiography, n.a. not applicable 
Table 5 Echocardiographic findings in patients $\leq 60$ years

\begin{tabular}{|c|c|c|c|}
\hline Cardiac risk factors in patients $\leq 60$ years & TTE & TEE & p-value \\
\hline & & & major cardiac risk factors \\
\hline$L V-E F<30 \%$ & $1(2.4 \%)$ & n.a. & n.a \\
\hline LA thrombus & none & none & n.a \\
\hline LAA thrombus & none & none & n.a \\
\hline LV thrombus & none & none & n.a \\
\hline mitral valve stenosis & none & none & n.a \\
\hline atrial myxoma & none & $1(2.4 \%)$ & n.a \\
\hline infective endocarditis & none & none & n.a \\
\hline \multirow[t]{2}{*}{ cardiac fibroma } & none & $1(2.4 \%)$ & n.a \\
\hline & & & Minor cardiac risk factors \\
\hline mitral valve prolapse & none & $4(9.5 \%)$ & $p=0.125$ \\
\hline mitral annular calcification & $1(2.4 \%)$ & $4(9.5 \%)$ & $p=0.250$ \\
\hline calcified aortic stenosis & none & none & n.a. \\
\hline patent foramen ovale & $13(31 \%)$ & $12(28.6 \%)$ & $p=1.000$ \\
\hline spontaneous echo contrast & none & none & n.a. \\
\hline atrial septum aneurysm & $4(9.5 \%)$ & $7(16.7 \%)$ & $p=0.375$ \\
\hline left ventricular aneurysm & none & none & n.a. \\
\hline aortic plaque & none & $6(14.25 \%)$ & $p=0.031$ \\
\hline
\end{tabular}

$\overline{T T E}$ transthoracic echocardiography, TEE transesophageal echocardiography, $L V$-EF left ventricular ejection fraction, $L A$ left atrium, $L A A$ left atrial appendage, $L V$ left ventricle, n.a. not applicable

\section{Discussion}

Echocardiography revealed abnormal findings in $62 \%$ of patients, which in $22.5 \%$ lead to a change in therapeutic regime. TEE does give additional information with clinical relevance regarding detection of the etiology of stroke, but the number of abnormal findings leading to a change in the therapeutical regime, which were not primally detected in TTE is rather low (5\%). On the other hand, TTE revealed exclusive findings in stroke patients compared to TEE, e.g. reduced LV-EF and need of heart failure therapy or thrombi in the left ventricle. In our study major cardiac risk factors were found in $8.2 \%$ by TEE, especially left atrial thrombi were rare. Patients with sinus rhythm were infrequently detected with left atrial thrombi [10], therefore emphasis in clinical routine should be put on rhythm monitoring. Overall the prevalence of major cardiac risk factors was lower than in other studies [11], but we did not differentiate aortic plaques regarding their size and complexity in major and minor cardiac risk factors. Minor cardiac risk factors such as mitral valve annular calcifications or prolapse of the mitral valve were more frequent to be found in TEE than in TTE due to the better view on heart valves in TEE because their closer proximity of the imaging transducer ${ }^{12}$. But looking closer at those findings, they did not have any impact on the therapeutical regime. The most common finding in TEE was the plaque in the aortic arche. An aortic plaque $>4 \mathrm{~mm}$ is an independent risk factor of recurred stroke [12] and well detectable in TEE but not in TTE. However, it has been shown that a normal carotid intima-media-thickness has a negative predictive value for aortic plaques [13] and computed tomographic angiography has a negative predictive value for high grade aortic arche atheroma [14]. Furthermore, a therapy change after detection of aortic plaque is doubtful, since patients receive antithrombotic drugs after a stroke as part of the regular therapeutic regime or even, after a minor stroke or high-risk TIA, a dual platelet inhibition [14, 15]. Diagnostics of patent foramen ovale came more into focus since successful studies demonstrated the benefit of closure of PFO in younger patients with cryptogenic stroke [16-18]. Previous studies showed, that TEE is less sensitive in detection of PFO than transcranial doppler [6] and that the detection rate is lower in TTE than in TEE [5]. In contrast, our study revealed that TTE serves as a good screening tool for detection of PFO, since the detection rate is similar to TEE. Only the precision in the determination of the size of the patent foramen ovale seems to be better in TEE than in TTE, which has also been shown before [19]. In the subgroup analysis of the younger patients aged $\leq 60$ years, we found a higher rate of PFO with $28.6 \%$ as expected, but the detection rate of PFO was similar in TTE and TEE in this group. Only three major cardiac risk factors found in TEE in patients age $\leq 60$ years, leading to the suggestion/discussion if 
TEE should not be routinely performed in younger patients but rather could be reasonable in older stroke patients as suggested before [11] or dispensable under certain conditions, since the detection rate of PFO could be similar in TTE as in TEE. We excluded patients with clinically suspected endocarditis in our study, since TEE would be the method of choice in suspected endocarditis due to its higher sensitivity and specificity in diagnosis of endocarditis than TTE [20]. The aim of our study was not to examine the relevance of TEE in patients with a clear indication for it, but rather test its added diagnostic value compared to TTE in patients without classical indications for this procedure.

\section{Conclusions}

Major finding of echocardiography in stroke patients with clinical impact on therapy change is the detection of a relevant PFO. In this matter, TTE is equally sufficient to TEE, implicating a good screening tool for detection of PFO in cryptogenic stroke, especially in younger patients $\leq 60$ years. However, TEE remains the gold standard in specific situations or indications, such as endocarditis, obese patients and rare causes of embolic stroke (e.g. myxoma and fibroelastoma).

\section{Abbreviations}

TTE: Transthoracic echocardiography; TEE: Transesophageal echocardiography; PFO: Patent foramen ovale; ECG: Electrocardiogram; NIHS S: National Institute of Health Stroke Score; mRS: modified Rankin Scale; CVRF: Cardiovascular risk factors; LAA: Left atrial appendage; LA: Left atrium; LV: Left ventricle; ASA: Atrial septum aneurysm; ESUS: Embolic stroke of unknown source; ACA: Anterior cerebral artery; MCA: Middle cerebral artery; PCA: Posterior cerebral artery; BA: Basilar artery; LV-EF: Left ventricular ejection fraction

\section{Acknowledgements}

Not applicable.

\section{Authors' contributions}

Conceptualization: JL and MRS; methodology: JL, MRS and MS; formal analysis: MS; investigation: MC, MD, FW and IA; resources: MB; data curation: MS and MBa; writing —original draft preparation: MS; writing —-review and editing: $J$ and MRS; supervision: MB and GH; project administration: $J L$ and MRS. All authors read and approved the final manuscript.

\section{Funding}

Open Access funding enabled and organized by Projekt DEAL.

\section{Availability of data and materials}

The datasets generated and analysed during the current study are not publicly available due to the possibility of compromising individual privacy but are available from the corresponding author on reasonable request.

\section{Declarations}

\section{Ethics approval and consent to participate}

The trial was registered and approved prior to inclusion by the ethics committee of the University Medicine Göttingen (Ethikkommission der Universitätsmedizin Göttingen;1/3/17). All methods were carried out in accordance with the declaration of Helsinki. Written consent to participate was obtained from each patient.

\section{Consent for publication}

Not applicable.

\section{Competing interests}

The authors declare that they have no competing interests.

\section{Author details}

'Department for Cardiology \& Pneumology/Heart Center, University Medical Center Göttingen, Robert-Koch Straße 40, 37075 Göttingen, Germany.

${ }^{2}$ Department for Neurology, University Medical Center Göttingen,

Robert-Koch Straße 40, 37075 Göttingen, Germany.

Received: 10 November 2020 Accepted: 25 February 2021

Published online: 17 March 2021

\section{References}

1. Bonita R. Epidemiology of stroke. Lancet. 1992 Feb 8;339(8789):342-4.

2. Hart RG, Diener H-C, Coutts SB, Easton JD, Granger CB, O'Donnell MJ, et al. Embolic strokes of undetermined source: the case for a new clinical construct. Lancet Neurol. 2014;13(4):429-38.

3. Nakanishi K, Homma S. Role of echocardiography in patients with stroke. J Cardiol. 2016 Aug 1;68(2):91-9.

4. Meenan RT, Saha S, Chou R, Swarztrauber K, Pyle Krages K, O'Keeffe-Rosetti $M C$, et al. Cost-effectiveness of echocardiography to identify Intracardiac Thrombus among patients with first stroke or transient ischemic attack. Med Decis Mak. 2007;27(2):161-77.

5. de Bruijn SFTM, Agema WRP, Lammers GJ, van der Wall EE, Wolterbeek R, Holman ER, et al. Transesophageal echocardiography is superior to transthoracic echocardiography in Management of Patients of any age with transient ischemic attack or stroke. Stroke. 2006 Oct;37(10):2531-4.

6. Katsanos AH, Psaltopoulou T, Sergentanis TN, Frogoudaki A, Vrettou A-R, Ikonomidis l, et al. Transcranial Doppler versus transthoracic echocardiography for the detection of patent foramen ovale in patients with cryptogenic cerebral ischemia: a systematic review and diagnostic test accuracy meta-analysis. Ann Neurol. 2016;79(4):625-35.

7. Kasner SE, Swaminathan B, Lavados P, Sharma M, Muir K, Veltkamp R, et al. Rivaroxaban or aspirin for patent foramen ovale and embolic stroke of undetermined source: a prespecified subgroup analysis from the NAVIGATE ESUS trial. Lancet Neurol. 2018 Dec 1;17(12):1053-60.

8. Katsanos AH, Giannopoulos S, Frogoudaki A, Vrettou A-R, Ikonomidis I, Paraskevaidis I, et al. The diagnostic yield of transesophageal echocardiography in patients with cryptogenic cerebral ischaemia: a metaanalysis. Eur J Neurol. 2016;23(3):569-79.

9. Hart RG. Cardiogenic embolism to the brain. Lancet. 1992 Mar 7;339(8793): 589-94.

10. Agmon Y, Khandheria BK, Gentile F, Seward JB. Clinical and echocardiographic characteristics of patients with left atrial Thrombus and sinus rhythm: experience in 20643 consecutive transesophageal echocardiographic examinations. Circulation. 2002 Jan;105(1):27-31.

11. Young KC, Benesch CG. Transesophageal echocardiography screening in subjects with a first cerebrovascular ischemic event. J Stroke Cerebrovasc Dis. 2011 Nov 1;20(6):503-9.

12. French Study of Aortic Plaques in Stroke Group, Amarenco P, Cohen A, Hommel M, Moulin T, Leys D, et al. Atherosclerotic disease of the aortic arch as a risk factor for recurrent ischemic stroke. N Engl J Med. 1996; 334(19):1216-21.

13. Harloff A, Handke M, Geibel A, Oehm E, Guschlbauer B, Olschewski M, et al. Do stroke patients with normal carotid arteries require TEE for exclusion of relevant aortic plaques? J Neurol Neurosurg Psychiatry. 2005 Dec;76(12): 1654-8.

14. Johnston SC, Easton JD, Farrant M, Barsan W, Conwit RA, Elm JJ, et al. Clopidogrel and Aspirin in Acute Ischemic Stroke and High-Risk TIA. N Engl J Med. 2018; [cited 2019 Nov 2]; Available from: https://www.nejm.org/doi/1 0.1056/NEJMoa1800410.

15. Wang Y, Wang Y, Zhao X, Liu L, Wang D, Wang C, et al. Clopidogrel with Aspirin in Acute Minor Stroke or Transient Ischemic Attack; 2013. https://doi. org/10.1056/NEJMoa1215340. [cited 2019 Nov 2]. Available from: https:// www.nejm.org/doi/10.1056/NEJMoa1215340

16. Lee PH, Song J-K, Kim JS, Heo R, Lee S, Kim D-H, et al. Cryptogenic stroke and high-risk patent foramen Ovale: the DEFENSE-PFO trial. J Am Coll Cardiol. 2018 May 22;71(20):2335-42.

17. Mas J-L, Derumeaux G, Guillon B, Massardier E, Hosseini H, Mechtouff L, et al. Patent Foramen Ovale Closure or Anticoagulation vs. Antiplatelets after Stroke; 2017. https://doi.org/10.1056/NEJMoa1705915. [cited 2019 Nov 
5]. Available from: https://www.nejm.org/doi/10.1056/NEJMoa1705915?url_ ver=Z39.88-2003\&rfr_id=ori\%3Arid\%3Acrossref.org\&rfr_dat=cr_pub\%3

Dwww.ncbi.nlm.nih.gov

18. Søndergaard L, Kasner SE, Rhodes JF, Andersen G, Iversen HK, Nielsen-Kudsk $J$ E, et al. Patent Foramen Ovale Closure or Antiplatelet Therapy for Cryptogenic Stroke; 2017. https://doi.org/10.1056/NEJMoa1707404. [cited 2019 Nov 5]. Available from: https://www.nejm.org/doi/10.1056/NEJMoa1 707404?url_ver=Z39.88-2003\&rfr_id=ori\%3Arid\%3Acrossref.org\&rfr_dat=cr_ pub\%3Dwww.ncbi.nlm.nih.gov

19. Zhang L, Harrison JK, Goldstein LB. Echocardiography for the detection of cardiac sources of embolism in patients with stroke or transient ischemic attack. J Stroke Cerebrovasc Dis. 2012 Oct 1;21(7):577-82.

20. Benedetto U, Avtaar Singh SS, Spadaccio C, Moon MR, Nappi F. A narrative review of the interpretation of guidelines for the treatment of infective endocarditis. Ann Transl Med. 2020;8(23) [cited 2021 Jan 24]. Available from: https://www.ncbi.nlm.nih.gov/pmc/articles/PMC7791230/.

\section{Publisher's Note}

Springer Nature remains neutral with regard to jurisdictional claims in published maps and institutional affiliations.

Ready to submit your research? Choose BMC and benefit from:

- fast, convenient online submission

- thorough peer review by experienced researchers in your field

- rapid publication on acceptance

- support for research data, including large and complex data types

- gold Open Access which fosters wider collaboration and increased citations

- maximum visibility for your research: over $100 \mathrm{M}$ website views per year

At BMC, research is always in progress.

Learn more biomedcentral.com/submissions 